\title{
Screening techniques and sources of resistance to nematodes in cool season food legumes
}

\author{
S. B. Sharma ${ }^{1}$, R. A. Sikora ${ }^{2}$, N. Greco ${ }^{3}$, M. Di Vito ${ }^{3}$ \& G. Caubel ${ }^{4}$ \\ ${ }^{1}$ Legumes Pathology, ICRISAT, Patancheru P. O., Andhra Pradesh 502 324, India; ${ }^{2}$ Institut für Pflanzenkrankheiten \\ der Rheinischen Friedrich Wilhelms Universität, Nussallee 9, 5300 Bonn, Germany; ${ }^{3}$ Istituto di Nematologia \\ Agraria, C.N.R., 70126, Bari, Italy, and ${ }^{4}$ INRA, Laboratoire de Zoologie, 35650 Le Rheu, France
}

Key words: chickpea, cyst nematodes, faba bean, lentil, pea, root-knot nematodes, stem nematode

\begin{abstract}
Identification of sources of resistance in cool season legumes to cyst (Heterodera spp.), root-knot (Meloidogyne spp.), and stem nematode (Ditylenchus dipsaci) is generally based on number of cysts on roots, root-knot nematode induced gall index, and stem nematode reproduction in shoot tissue, respectively. Various levels of resistance to cyst nematodes have been detected in chickpea and pea. Resistance has also been identified in chickpea, faba bean, and pea to the root-knot nematodes. Broad based durable sources of resistance to plant parasitic nematodes are required. Basic research is needed to develop transgenic plants with resistance based on hatch stimulants, inhibitors, toxins, or repellents found in antagonistic rhizosphere microorganisms. Selection of genotypes that favor development of beneficial rhizosphere microorganisms or root endophytes that increase the plant resistance to nematode infection deserves attention.
\end{abstract}

\section{Introduction}

Many species of plant parasitic nematodes attack chickpea (Cicer arietinum L.), faba bean (Vicia faba L.), lentil (Lens culinaris Medik.), and pea (Pisum sativum L.). Cyst, root-knot, and stem nematodes are considered to be of widespread economic importance (Sikora \& Greco, 1990). These nematodes cause vascular disorders and suppress Rhizobium nodulation. Damage is amplified by synergistic interrelationships with soilborne diseases. Most growers, however, are not sufficiently aware of the magnitude of damage caused by nematodes to these crops. Control of nematodes with soil application of nematicides and soil solarization is effective but expensive (Sharma \& Nene, 1990; Di Vito et al., 1991). Seed treatment is not always effective and crop rotation is complicated due to a wide host range of root-knot and stem nematodes. For these reasons, exploitation of host plant resistance to important nematode pests has priority and has great potential. Cultivation of nematode-resistant cultivars is a simple and economical way to prevent nematode- caused damage and to avoid environmental pollution due to improper use of pesticides. Unfortunately, limited efforts have been made to identify sources of resistance and breed for nematode resistance in chickpea, faba bean, lentil, and pea. The first requirement in any program designed to breed for resistance to nematodes is to develop practicable and simple host-plant resistance screening methods that will result in reliable selection of resistant genotypes. Identification of host-plant resistance to nematodes is generally based on either measurement of reproduction of nematodes and in some cases such as the root-knot nematodes and stem nematodes on symptoms produced (root galls, swelling of the stem).

This paper concentrates on important nematode pests of chickpea, faba bean, lentil, and pea, techniques for identification of host plant resistance, identified sources of resistance, and perspectives for future research. 


\section{Chickpea}

Root-knot nematodes, Meloidogyne incognita (Kofoid and White) Chitwood, M. javanica (Treub) Chitwood, $M$. artiellia Franklin and chickpea cyst nematode, Heterodera ciceri Vovlas, Greco and Di Vito(Vovlas et al., 1985) are economically important nematode pests of chickpea (Sikora \& Greco, 1990).

\section{Meloidogyne incognita and $M$. javanica}

These two species of root-knot nematodes are the most important nematode pests of chickpea in many countries, particularly India, Nepal, and Pakistan (Greco \& Sharma, 1990; Sharma \& McDonald, 1990; Sharma et al., 1990). Nematode infection does not produce any characteristic symptoms on aerial parts but reduces plant vigor, delays flowering, and induces early senescence - symptoms that are often confused with poor soil fertility and low moisture. Root galls are the most characteristic symptom of nematode infection. The galls are easily seen with the unaided eye. The tolerance limit (number of nematodes a plant can host without any measurable damage) of chickpea to these nematodes ranges from 0.2 to 2.0 eggs and juveniles $\mathrm{cm}^{-3}$ soil at sowing. These nematode species interfere with nitrogen fixation and increase the incidence of Fusarium wilt.

\section{Screening techniques}

Evaluation of host-plant resistance to $M$. javanica and $M$. incognita is largely based on the number of galls produced on roots of a plant. To screen for resistance, chickpea genotypes are evaluated either in a greenhouse or in nematode-sick fields.

\section{Greenhouse screening}

Population densities of the root-knot nematodes are increased on susceptible host plant cultivars (e.g., tomato, chickpea) in sandy soils in large pots. The nematode-infested soil obtained from these pots is added to 15-cm-diameter pots and seeds of chickpea genotypes are sown in pots. Alternatively, the infected roots of tomato and chickpea are chopped and thoroughly mixed with the soil before filling in the pots; or the infected roots of about 60-day old plants are washed free of soil, cut into $1-2 \mathrm{~cm}$ long segments, the nematode egg masses dissolved in $1.0 \%$ sodium hypochlorite, and the eggs released are counted (Hussey \& Bark- er, 1973). The egg suspension can be stored at $10^{\circ} \mathrm{C}$ for two weeks until used. Storage for a longer period, although possible, is not recommended. Seeds of chickpea genotypes are sown in 10 to 15 -cm-diameter pots and then 5- to 10-day old seedlings are inoculated with 5,000 to 10,000 eggs per plant by pouring the egg suspension into four 3 to $5 \mathrm{~cm}$ deep holes, around the stem base. After inoculation, pots are irrigated lightly to assure survival and even distribution of the nematode inoculum. Pots are kept at $25 \pm 5^{\circ} \mathrm{C}$ in a greenhouse.

\section{Field screening}

Root-knot nematode infested fields are identified and the population density of the nematode species $(M$. javanica or $M$. incognita) is enhanced by growing susceptible cultivars. Chickpea genotypes are sown in $4 \mathrm{~m}$ rows with $10 \mathrm{~cm}$ plant-to-plant spacing and $30 \mathrm{~cm}$ between the rows. Two rows of highly susceptible chickpea genotypes (e.g., ICCC 4 and Dhanush) are sown after every 10 test entries. Each test entry is replicated at least three times and all the genotypes are evaluated for number of galls or egg masses per plant generally near crop maturity (Manandhar et al., 1989). Root-knot or egg mass indices of each test genotype are compared with those of the checks.

\section{Resistance evaluation}

For determining resistance, genotypes are evaluated for number of galls and number of egg masses per root after 60 days on a 0 to 5 or 1 to 5 or 1 to 9 scale (Table 1).

Chickpea genotypes are also evaluated for tolerance to root- knot nematodes by comparing plant growth in nematode-infested soil with plant growth in nematodefree soil. The differences in biomass of promising tolerant plants in infested and nematode-free soil are not statistically significant $(\mathrm{P} \leq 0.05)$.

\section{Sources of resistance}

Resistance in chickpea germplasm to $M$. javanica and $M$. incognita has been reported in India (Sandhu et al., 1981; Hasan, 1983; Handa et al., 1985; Sharma \& Mathur, 1985; Gupta \& Verma, 1989; Pandey \& Singh, 1990). However, level of resistance in these sources needs reconfirmation. Manandhar et al., (1989) screened 267 promising chickpea genotypes in a field naturally infested with $M$. incognita race 2 and $M$. javanica. Many of the test genotypes had been 
Table 1. Resistance evaluation scales used for screening chickpea genotypes for resistance to Meloidogyne incognita and $M$. javanica

\begin{tabular}{lrrl}
\hline $\begin{array}{l}\text { Gall index or } \\
\text { egg mass index }\end{array}$ & \multicolumn{2}{c}{$\begin{array}{r}\text { Number of galls or } \\
\text { egg masses per plant }\end{array}$} & Reaction \\
\hline $1(1)$ & 0 & $(0)$ & Immune/Highly resistant \\
$2(3)$ & $1-10$ & $(1-10)$ & Resistant \\
$3(5)$ & $11-30$ & $(11-30)$ & Moderately resistant \\
$4(7)$ & $31-100$ & $(31-50)$ & Susceptible \\
$5(9)$ & $>100$ & $(>50)$ & Highly susceptible \\
\hline
\end{tabular}

1 to 5 and 1 to 9 (in parentheses) rating scales are generally used;

0 to 5 scale (as given for $M$. artiellia) can also be used. A 1 to 5 scale

based on $\%$ galling of roots; $1=$ no galling; $2=1$ to $25 \%$ galling; $3=26$ to

$50 \%$ galling; $4=51$ to $75 \%$ galling, and $5=76$ to $100 \%$ galling is also used.

reported resistant to root-knot nematodes in greenhouse tests in India. All the genotypes were susceptible and only two genotypes (ICC 5875 and ICC 6371) were found to be "less susceptible" with fewer than 50 galls per plant. At ICRISAT, 1000 chickpea genotypes and 35 accessions of wild species of Cicer have been evaluated for resistance to $M$. javanica. Bheema, N 31, N 59 and ICCC 42 were tolerant and the other genotypes were susceptible (S.B. Sharma, unpublished).

\section{Meloidogyne artiellia}

This root-knot nematode was first described in England and has gradually spread in the Mediterranean basin (Sikora \& Greco, 1990). It causes severe damage to chickpea in northern Syria, Italy, and Spain. Spring chickpea suffers more damage than winter chickpea. The tolerance limit is 0.01 eggs and juveniles $\mathrm{cm}^{-3}$ soil in spring and 0.14 eggs and juveniles $\mathrm{cm}^{-3}$ soil in winter (Di Vito \& Greco, 1988). Legumes, cereals and crucifers are good hosts of the nematode (Di Vito et al., 1985).

\section{Screening techniques}

Meloidogyne artiellia reproduces well on chickpea and durum wheat at $20 \pm 5^{\circ} \mathrm{C}$. Greenhouse and field screening procedures are essentially similar to those described for $M$. incognita and $M$. javanica. $M$. artiellia prefers lower temperatures than the other species of Meloidogyne, with an optimum between 15 and $25^{\circ} \mathrm{C}$ for development, activity and reproduction; therefore, pots are kept at $20 \pm 5^{\circ} \mathrm{C}$ in the greenhouse. The genotypes are evaluated for number of galls and egg masses per root 60 days later on a 0 to 5 scale, where $0=0$ galls or egg masses, $1=1$ to $2,2=3$ to $10,3=11$ to $30,4=31$ to 100 , and $5=$ more than 100 galls and/or egg masses (Taylor \& Sasser, 1978). Galls caused by $M$. artiellia are either very small (as with Syrian populations) or absent (as with Italian populations). Therefore, evaluation on the basis of number of egg masses is more reliable (Table 1 ).

\section{Sources of resistance}

Chickpea cultivars with resistance to $M$. artiellia have not been detected. However, evaluation of accessions of Cicer spp. have indicated availability of resistance in $C$. judaicum, $C$. pinnatifidum, $C$. chorassanicum, and $C$. cuneatum (Di Vito, unpublished).

\section{Heterodera ciceri}

The chickpea cyst nematode, $H$. ciceri, is widespread in northern Syria (Greco et al., 1984) and causes severe damage when its population at sowing exceeds $1 \mathrm{egg}$ $\mathrm{g}^{-1}$ soil (Greco et al., 1988). Yield losses of 20 and $50 \%$ have been estimated in fields infested with 8 and 16 eggs $^{-1}$ soil, respectively. Complete crop failure may occur at $\geq 32 \mathrm{eggs}^{-1}$ soil (Greco et al., 1988). 


\section{Screening technique}

Inoculum of $H$. ciceri is produced in high number on susceptible host plants. To evaluate chickpea for resistance to $H$. ciceri, test genotypes are sown in pots filled with steam-sterilized soil containing $80 \%$ sand, $15 \%$ loam, and 5\% clay that are artificially infested with 20 or more eggs and juveniles $\mathrm{g}^{-1}$ soil. Size of the pots and number of seedlings per pot may vary, but pots must be at least $10 \mathrm{~cm}$ in diameter to contain one plant per pot. Pots containing about $3,000 \mathrm{~cm}^{3}$ soil and four chickpea plants have been found to give reliable results. Pots are maintained in a greenhouse at $20 \pm$ $5^{\circ} \mathrm{C}$.

\section{Resistance evaluation}

Evaluation of plant reaction to infection is based on number of females and/or cysts per root. Roots of test genotypes are rated on a 0 to 5 scale (where $0=$ no females, $1=1$ to 2 females, $2=3$ to 5 females, $3=6$ to 20 females, $4=21$ to 50 females, and $5=$ more than 50 females per root) 45 days after seedling emergence ( $\mathrm{Di}$ Vito et al., 1988). Genotypes with an average rating of $\leq 2$ are considered resistant. If there is a need to obtain seeds from the resistant plants, seeds are sown in thin-walled 6 to 7 -cm-diameter black plastic pots, containing noninfested soil, and having 4 to 6 holes at the bottom (Wyatt \& Fassuliotis, 1979). These thinwalled pots are then buried in larger pots containing nematode-infested soil. After 60 days, the small pots are gently removed from the larger pots to recover roots growing in the infested soil of the large pots. These roots are washed free of adhering soil and scored for number of nematode females. Resistant plants are then transplanted in sterilized soil. Roots of these plants have not been seriously injured and the plants are able to produce seeds.

\section{Sources of resistance}

More than 9,000 chickpea lines have been screened and most of them have been rated as 4 and 5 (Di Vito et al., 1988, 1992). A small number of lines were rated as 3 and were considered as moderately resistant. No line has been found to be resistant. However, resistance is available in Cicer bijugum, $C$. reticulatum, and C. pinnatifidum (Singh et al., 1989; Di Vito et al., 1992). Resistance in accessions of $C$. reticulatum also is promising because this species can be crossed easily with $C$. arietinum and therefore can be useful in future breeding programs.

\section{Faba bean}

The most important nematode pests of faba bean are the stem nematode, Ditylenchus dipsaci (Kuhn) Filipjev, and the pea cyst nematode, Heterodera goettingiana Liebscher, and to a lesser extent species of Meloidogyne (Sikora \& Greco, 1990).

\section{Ditylenchus dipsaci}

Stem nematode is an important pest in most regions where faba bean is grown. Air temperatures of $15^{\circ}$ to $20^{\circ} \mathrm{C}$, high humidity, rain, fog, dew and sprinkler irrigation favor nematode infection, and disease development. The nematode withstands desiccation for many years and can survive for years in soil in the absence of a host plant or in seed in storage. Nematode infection causes severe distortions, swelling of the stem, and necrosis of all aerial parts. Disease development is greatly influenced by environmental conditions. In the Mediterranean region, where the nematode is widespread, these conditions occur from late fall to early spring. Several races of the nematode have been identified and faba beans are attacked by "giant" and "normal" races in winter and spring. The giant race, common in North Africa, is the most damaging to faba bean, especially when nematode-infested seed is sown.

\section{Screening technique}

Screening procedures have been developed to estimate resistance in faba bean in pots under controlled environment conditions (Sturhan, 1975; Hooper, 1983; Caubel \& Leclercq, 1989a) and in nematode-infested fields (Hanounik et al., 1986).

\section{Greenhouse screening}

The nematode reproduces on susceptible faba bean cultivars (Hooper, 1983) or on callus tissue (Riedel \& Foster, 1970) and can be easily extracted with the incubation (Young, 1954) or centrifuge (Coolen, 1979) methods. Nematodes in water are stored at $10^{\circ} \mathrm{C}$ until used and are concentrated to obtain about 100 nematodes in a drop of water. Seeds of test genotypes are sown on perlite at $23^{\circ} \mathrm{C}$ and 5-day old seedlings are transplanted into $15-\mathrm{cm}$-long and $2.5-\mathrm{cm}$-diameter glass tubes or in 
Table 2. Resistance evaluation scale used for field screening of faba bean genotypes for resistance to Ditylenchus dipsaci

\begin{tabular}{llr}
\hline Score & Symptoms & $\begin{array}{l}\text { Infected } \\
\text { plants (\%) }\end{array}$ \\
\hline 1 & No infection or very small stem swellings & 0 \\
3 & Few stem infections & $<20$ \\
5 & Stem and leaf swellings & $21-50$ \\
7 & Stunting, elongated necrotic stem & $51-75$ \\
& infections and moderate defoliation & $>75$ \\
9 & Severe stunting, giant necrotic & \\
\hline
\end{tabular}

small pots filled with organic sterilized compost (Ait Ighil, 1983). After a week, seedlings are inoculated with the nematode suspension in the leaf axil (Sturhan, 1975). The inoculated seedlings are placed at 15 to $20^{\circ} \mathrm{C}$ in a growth chamber. High humidity is required for several days to favor nematode infection.

\section{Field screening}

For screening in the field, large quantities of $D$. dipsaciinfected stems are collected from infested fields, cut into 2-cm segments, and mixed thoroughly with soil in a ratio of 1:1 (v:v). After two weeks, the infested soil is diluted with a nematode-free soil until a population density of about 300 larvae $1000 \mathrm{~cm}^{-3}$ soil is obtained. Seeds are sown in rows $1 \mathrm{~m}$ long and $50 \mathrm{~cm}$ apart. A susceptible cultivar row is planted after every five test rows. All seeds are covered with infested soil to a depth of $15 \mathrm{~cm}$. Data are recorded, using a scale based on symptoms (Table 2 ), at about $80 \%$ podding when symptoms on the stem are well developed (Hanounik et al., 1986).

\section{Resistance evaluation}

The nematode produces characteristic symptoms of swelling or necrosis near the inoculation site generally 8 weeks after inoculation. These symptoms are useful in differentiating susceptible and resistant plants. Plant reaction can be confirmed by measuring nematode reproduction 12 weeks after inoculation. All faba bean genotypes showing a reproduction rate of less than one are considered resistant. Reproduction rate in susceptible plants is high and may reach more than
100. A good correlation exists between symptoms on the stem and reproduction rates of the nematode.

\section{Sources of resistance}

Resistance to $D$. dipsaci in faba bean has been identified. Schreiber (1977) reported a Moroccan faba bean cultivar (Souk el Arba du Rharb) having resistance to D. dipsaci. Abbad et al. (1990) found resistance in Moroccan lines and in germplasm lines of faba bean. Hanounik et al. (1986) found 11 germplasm lines resistant to Tunisian populations of $D$. dipsaci and 12 lines resistant to Syrian populations. Field beans ( $V$. faba ssp. minor) are generally poorer hosts than broad beans (V. faba ssp. faba). The field bean cultivar "Diana" is not a good host in comparison with broad bean cultivar "Hedosa" (Augustin \& Sikora, 1989). Caubel \& Leclercq (1989b) found faba bean line INRA 29H resistant to "giant" race of the nematode. No information is so far available on the genes conferring resistance to $D$. dipsaci. Limited information is available on the reaction of other Vicia spp. to $D$. dipsaci. Accessions of $V$. cracca, $V$. sativa, and $V$. villosa are susceptible. Two accessions of $V$. narbonensis have resistance to the nematode.

\section{Heterodera goettingiana}

The pea cyst nematode is an important pest of faba bean in many temperate regions and is a limiting factor in the cool-growing season in some countries. Greco et al. (1991) found that the tolerance limit of faba bean to $H$. goettingiana is $0.8 \mathrm{eggs} \mathrm{g}^{-1}$ soil, and yield losses of 20 and $50 \%$ are expected in soils infested with five and 15 eggs $\mathrm{g}^{-1}$ soil, respectively, while complete crop failure occurs at $\geq 64 \mathrm{eggs} \mathrm{g}^{-1}$ soil. Heterodera goettingiana is widespread in Europe and in the Mediterranean basin (Di Vito \& Greco, 1986).

\section{Screening technique}

The nematode reproduces on faba bean, pea, grasspea, and vetch and its population can be increased by rearing it on host plants in pots kept in greenhouses at about $20^{\circ} \mathrm{C}$ or outdoors (from mid-autumn to mid-spring under Mediterranean climates). Faba bean germplasm can be evaluated for resistance to $H$. goettingiana using the screening procedure suggested for chickpea to $H$. ciceri. Number of cysts on roots can be counted at flowering to early podding stage. Soil and environmental conditions for development and repro- 
duction of the nematode are similar to that of $\mathrm{H}$. ciceri. More details on host reaction can be obtained by determining the reproduction rate of the nematode. All germplasm lines giving nematode reproduction rates of $\leq 1$ are considered as highly resistant.

\section{Sources of resistance}

So far no faba bean cultivar has been reported as resistant to $H$. goettingiana, nor is there any germplasm screening in progress.

\section{Lentil}

Heterodera ciceri is one of the important nematode pests of lentil in northern Syria (Greco et al., 1984; Vovlas et al., 1985). However, lentil is less susceptible to $H$. ciceri than chickpea. The tolerance limit for lentil is 2.5 eggs $\mathrm{g}^{-1}$ soil (Greco et al., 1988). Yield losses of 30 and $50 \%$ occur in fields infested with 32 and 128 eggs $\mathrm{g}^{-1}$ soil, respectively.

\section{Screening technique}

The screening techniques described for the evaluation of chickpea genotypes for resistance to this nematode are also used for lentil.

\section{Sources of resistance}

Screening of lentil germplasm in Syria (ICARDA, 1985) demonstrated that although lentil lines differed in their reaction to this nematode, none were resistant.

\section{Pea}

Pea is a good host of many nematode species (Sikora \& Greco, 1990). However, under field conditions only the pea cyst nematode, $H$. goettingiana and the root-knot nematodes, Meloidogyne spp. are important. There have been few reports of root-knot nematodes causing severe damage to pea when grown in the cool season. Resistance in pea to root-knot nematodes has been reported and is extremely important wherever peas are grown as a summer crop (Tanveer \& Saad, 1971). Microplot experiments have shown that the tolerance limit of pea to $H$. goettingiana is $0.5 \mathrm{eggs}^{-1}$ soil (Greco et al., 1991). Yield losses of 20 and 50\% as well as complete crop failure are expected when pea is cultivated in soils with two, eight, and 32 eggs of H. goettingiana $\mathrm{g}^{-1}$ soil, respectively, (Greco et al., 1991). Stem nematode is considered as a minor pest of pea and nematode infection causes discoloration of the stem.

\section{Screening technique}

Nematode-infested sandy soil containing 20 eggs and juveniles is filled in pots and seeds of test genotypes are sown in November in a greenhouse at $15^{\circ} \mathrm{C}$. Roots are evaluated for number of females and cysts after two months. Number of cysts on a test genotype is compared with number of cysts on a check cultivar (e.g., "Verdone Fulminate", "Progress 9") and genotypes with cysts numbering 1 to $5 \%$ of the check are considered as resistant, and those with cysts numbering 6 to $15 \%$ of the check are considered to be moderately resistant (Di Vito \& Perrino, 1978).

\section{Sources of resistance}

Although cultivars with resistance to $H$. goettingiana have not been marketed commercially, accessions of Pisum sativum ssp. abyssinicum (A. Braun) Govorov, $P$. sativum ssp. sativum var. arvense (L.) Poir, and $P$. sativum ssp. elatius (M. Bieb.) Aschers. \& Graebn. var. elatius (M. Bieb.) Alef. have been shown to be moderately resistant to $H$. goettingiana (Di Vito \& Perrino, 1978). Interspecific crosses between susceptible $P$. sativum cultivar Progress 9 and resistant $P$. sativum ssp. abyssinicum (MG 101791) are moderately resistant to the nematode in the $F_{2}$ generation indicating that resistance is recessive (Di Vito \& Greco, 1986).

\section{Concluding remarks}

Research on nematode pests of chickpea, faba bean, lentil, and pea has not received due attention and a limited number of nematologists are working on identification of host-plant resistance in these crops to important nematode species. This is largely because of lack of awareness about the economic importance of nematode-caused damage to these crops. In addition, there are not enough trained nematologists in the developing countries to identify, investigate, and demonstrate nematode disease and losses in farmers' fields. Availability of trained staff in the national programs of developing countries is essential for tangible progress in management of losses caused by nema- 
todes using host-plant resistance. At present, identification of resistant sources is largely done in the greenhouse. Efforts should be made to develop field screening methods. Screening in greenhouses should be used as a supplement to field screening. Once resistant genotypes are identified, multilocational testing of these genotypes at hot spot locations is essential to evaluate their resistance against different populations (races) of the nematodes and to investigate the agronomic performance of the promising cultivars under different environmental situations. Use of nematode tolerant cultivars to limit economic losses in nematodeinfested areas should be encouraged. Tolerant cultivars have one advantage over resistant cultivars in that they reduce yield losses from nematodes without providing selection pressure on the nematode for development of more aggressive races. More fundamental studies are required on biodiversity and coevolution to understand variability in races of nematodes, evolution of virulence genes in nematode populations, and mechanisms of resistance at biochemical and molecular levels. In addition to the on-going research on post-infectional resistance (based on galls, cysts, etc.), basic research is needed to identify genotypes with morphological and physiological preinfectional resistance. This will help in developing transgenic plants with resistance based on egg hatch inhibition, toxins, or repellents. A number of major advances have been made in developing techniques for screening rhizosphere bacteria for toxic as well as microbial metabolites that adversely affect nematode behavior (Sikora, 1991). In both cases, the presence of these organisms leads to increased plant health by either protection of the root surface from infection or through direct toxicity to the nematode parasite. A number of bacterial antagonists, for example, have been detected which are able to reduce hatch and mobility, as well as root recognition and penetration processes (Oostendorp \& Sikora, 1989). These organisms could serve as a basis for future engineered plants. Fungal antagonists which produce nematicidal protein based compounds that degrade egg wall material have also been detected (Sikora et al., 1990). In addition, fungal endophytes which live within the tissue of roots have been shown to prevent nematode penetration (Pedersen et al., 1988), whereas others inactivate endoparasitic nematodes through specific metabolites. These fungi also could serve as a bank for future resistance breeding programs.

It should be mentioned that the development of gene engineered plants will not necessarily solve the problems associated with the selection of patho- types out of naturally occurring nematode populations. Therefore, judicious use of resistant plants whatever their origin will be necessary.

\section{References}

Abbad, F.A., M. Ammati \& R. Alami, 1990. In: Proceedings of 8th Congress of the Mediterranean Phytopathological Union, pp. 347-349. Agadir, Morocco.

Ait Ighil, M., 1983. Variabilité physiologique de deux races, normale et géante, de Ditylenchus dipsaci (Kuhn) Fil. (Nematoda: Tylenchida), parasites de Vicia faba L, $106 \mathrm{pp}$. Thèse Ingenieur Docteur, ENSA, Université des Sciences Rennes.

Augustin, B. \& R.A. Sikora, 1989. Gesunde Pflanzen 5: 189-192.

Caubel, G. \& D. Leclercq, 1989a. Nematologica 35: 216-224.

Caubel, G. \& D. Leclercq, 1989b. Fabis 25: 45-47.

Coolen, W.A., 1979. In: F. Lamberti \& C.E. Taylor (Eds.), Rootknot nematodes (Meloidogyne species) systematics, biology and control, pp. 317-329. Academic Press, London, UK

Di Vito, M. \& N. Greco, 1986. In: F. Lamberti \& C.E. Taylor (Eds.), Cyst nematodes, pp. 321-332. Plenum Press, New York, USA.

Di Vito, M. \& N. Greco, 1988. Nematologia Mediterranea 16: 163166.

Di Vito, M., N. Greco \& M.C. Saxena 1991. Nematologia Mediterranea 19: 109-111.

Di Vito, M., N. Greco, K.B. Singh \& M.C. Saxena, 1988. Nematologia Mediterranea 16: 17-18.

Di Vito, M., N. Greco, K.B. Singh \& M.C. Saxena, 1992. Sources of resistance to Heterodera ciceri in Cicer spp. 21st International Nematology Symposium of ESN, Albufeira, Portugal, 11-17 April, 1992.

Di Vito, M., N. Greco \& G. Zaccheo, 1985. Nematologia Mediterranea 13: 207-212.

Di Vito, M. \& P. Perrino, 1978. Nematologia Mediterranea 6: $113-$ 118.

Greco, N., M. Di Vito, M.V. Reddy \& M.C. Saxena, 1984. Nematologia Mediterranea 12: 87-93.

Greco, N., M. Di Vito, M.C. Saxena \& M.V. Reddy, 1988. Nematologica 34: 98 -114.

Greco, N., H. Ferris \& A. Brandonisio, 1991. Revue de Nematologie 14: 619-624.

Greco, N. \& S.B. Sharma, 1990. In: H.A. van Rheenen, M.C. Saxena, B.J. Walby \& S.D. Hall (Eds.), Chickpea in the nineties, pp. 135 137. ICRISAT, Patancheru, Andhra Pradesh, India.

Gupta, D.C. \& K.K. Verma, 1989. Haryana Agricultural University Journal of Research 19: 318-320.

Handa, D.K., K.K. Jain, A. Mishra \& S.M. Bhatnagar, 1985. International Chickpea Newsletter 12: 33.

Hanounik, S.B., H. Halila \& M. Harrabi, 1986. Fabis 16: 37-39.

Hasan, A., 1983. International Chickpea Newsletter 8: 26-27.

Hooper, D.J., 1983. Rothamsted Report Part 2: 239-260.

Hussey, R.S. \& K.R. Barker, 1973. Plant Disease Reporter 57: 10251028.

ICARDA, 1985. Studies on nematodes of food legumes, 25 pp. Progress Report 1984/1985. ICARDA, Aleppo, Syria.

Manandhar, H.K., S.B. Sharma \& O. Singh, 1989. International Chickpea Newsletter 20: 14.

Oostendorp, M. \& R.A. Sikora, 1989. Revue de Nematologie 12: 77-83.

Pandey, G. \& R.B. Singh, 1990. Current Nematology 1: 71-72. 
Pedersen, J.F., R. Rodriguez-Kabana \& R.A. Shelby, 1988. Agronomy Journal 88: 811-814.

Riedel, R.M. \& J.G. Foster, 1970. Plant Disease Reporter 54: 251254.

Sandhu, T.S., B.S. Kooner, I. Singh \& K. Singh, 1981. Indian Journal of Nematology 11: 86-87.

Schreiber, E.R., 1977. Lebensweise, Bedeutung und Bekampfungsmoglichkeiten von Ditylenchus dipsaci (Kuhn) Filipjev an Ackerbohne (Vicia faba L.) in Marokko. Dissertation der Technischen Universitat, Berlin. D83 No. 79, 150 pp.

Sharma, G.L. \& B.N. Mathur, 1985. International Chickpea Newsletter 12: 31-32.

Sharma, S.B. \& D. McDonald, 1990. Crop Protection 9: 453-458.

Sharma, S.B. \& Y.L. Nene, 1990. Joumal of Nematology 22S: 579584.

Sharma, S.B., R.P. Saha, O. Singh \& H.A. Van Rheenen, 1990. Tropical Pest Management 36: 327-328.

Sikora, R.A., 1991. In: C. Keel, B. Koller \& G. Defago (Eds.), Plant growth-promoting Rhizobacteria - progress and prospects, pp. 3-10. Interlaken, Switzerland.
Sikora, R.A. \& N. Greco, 1990. In: M. Luc, R.A. Sikora \& J. Bridge (Eds.), Plant-parasitic nematodes in subtropical and tropical agriculture, pp. 181-235. CAB International Publishers, Wallingford, UK.

Sikora, R.A., M. Hiemer \& R.P. Schuster, 1990. Mededelingen van de Faculteit Landbouwwetenschappen Rijksuniversiteit Gent 55 699-712.

Singh, K.B., M. Di Vito, N. Greco \& M.C. Saxena, 1989. Nematologia Mediterranea 17: 113-114.

Sturhan, D., 1975. Mededelingen van de Faculteit Landbouwwetenschappen Rijksuniversiteit Gent 40: 443-450.

Tanveer, M. \& A.T. Saad, 1971. Plant Disease Reporter 55: 1082 1084.

Taylor, A.L. \& J.N. Sasser, 1978. Biology, identification and control of root-knot nematodes (Meloidogyne species), 111 pp. North Carolina State University Graphic, Raleigh, NC, USA.

Vovlas, N., N. Greco \& M. Di Vito, 1985. NematologiaMediterranea 13: 239-252.

Wyatt, J.E. \& G. Fassuliotis, 1979. HortScience 14: 27-28.

Young, T.W., 1954. Plant Disease Reporter 38: 794-795. 